\title{
DESAFIOS DA EDUCAÇÃO REFLETIDOS E REFRATADOS NA MÍDIA DURANTE A PANDEMIA COVID19
}

\section{EDUCATION CHALLENGES REFLECTED AND REFRACTED IN THE MEDIA DURING PANDEMIC COVID19}

\author{
Sonia Sueli Berti Pinto', Miriam Bauab Puzzo²
}

\begin{abstract}
Submetido em: 03/04/2021
Aprovado em: 23/04/2021
\end{abstract}

\section{RESUMO}

O objetivo deste artigo é lançar luz sobre a questão da educação no contexto atual brasileiro e como os problemas se refletem e se refratam na mídia impressa como as crônicas e as charges. Para discutir a linguagem, as atitudes responsivas e responsáveis de seus enunciadores, assim como o posicionamento axiológico de ambos, tomam-se como referência a teoria dialógica da linguagem na perspectiva de Bakhtin e do Círculo, assim como autores que tratam da linguagem verbo-visual, Brait e Dondis. Como objeto investigativo, foi selecionada a crônica "Tela, cautela, nutella", de Antonio Prata, publicada na Folha de S. Paulo em 12/09/2020 e três charges assinadas por Caco Galhardo publicadas na revista Piauí, no 164 de maio 2020.

PALAVRAS-CHAVE: Análise dialógica da linguagem. Mídia. Linguagem verbo-visual.

\begin{abstract}
The purpose of this article is to shed light on the issue of education in the current Brazilian context and how the problems are reflected and refracted in the printed media such as chronicles and cartoons. To discuss language, the responsive and responsible attitudes of its enunciators, as well as the axiological positioning of both, the dialogical theory of language is taken as a reference from the perspective of Bakhtin and the Circle, as well as authors who deal with the verb-visual language, Brait and Dondis. As an investigative object, we selected the chronicle "Tela, cautela, nutella", by Antonio Prata, published in Folha de S. Paulo on 12/09/2020 and three cartoons signed by Caco Galhardo published in Piauí magazine, no 164 of May 2020.
\end{abstract}

KEYWORDS: Education. Media. Discourse. Verb-visual language. Critical positioning.

\section{INTRODUÇÃO}

O problema que motivou esta pesquisa é a situação caótica que a educação no Brasil enfrenta, desorientando escolas, professores, pais e alunos, confinados ao espaço doméstico, recebendo aulas virtuais de difícil concentração para crianças e adolescentes. Portanto, o objetivo desta comunicação é discutir o discurso midiático verbo-visual que reflete e refrata na linguagem as informações sobre a educação no contexto atual brasileiro que se defronta com problemas políticos educacionais num momento crítico pela pandemia.

A teoria que fundamenta essa discussão toma como referência os documentos oficiais que regulam a educação no Brasil como o Decreto 9.235 de 15 de dezembro de 2017, a Lei oㅜ 13.979, de 06 de fevereiro de 2020, a Portaria ํㅜ 544, de 16 de junho de 2020, Parecer CNE/CP no 11 de 7 de

\footnotetext{
${ }^{1}$ Mestrado e Doutorado em Linguística e Semiótica - USP/SP; Pós-doutorado em Linguística Aplicada - PUC/SP - https://orcid.org/0000-0003-2588-4140

2 Doutorado - Mestrado em Teoria Literária - USP/SP; Doutorado em Letras - USP/SP e Pós-Doutorado em Linguística Aplicada PUC/SP - https://orcid.org/0000-0002-0046-7159
} 


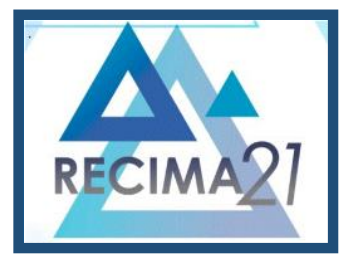

\section{RECIMA21 - REVISTA CIENTÍFICA MULTIDISCIPLINAR}

DESAFIOS DA EDUCAÇÃo REFLETIDOS E REFRATADOS NA MÍDIA DURANTE A PANDEMIA COVID19 Sonia Sueli Berti Pinto, Miriam Bauab Puzzo

julho de 2020, que deliberam sobre as ações a serem tomadas durante a pandemia e sobre o trabalho docente de modo remoto, entre outros, assim como analisa a linguagem na perspectiva da Teoria Dialógica da Linguagem de Bakhtin e o Círculo com apoio nas categorias de gênero discursivo (BAKHTIN, 2016), signo ideológico e posicionamento responsivo e valorativo dos enunciadores (VOLÓCHINOV, 2017), linguagem verbo-visual (BRAIT, 2010, 2013,2014).

Para cumprir esta proposta foram selecionadas três charges publicadas na revista Piauí 164 de maio 2020 e a crônica "Tela, cautela, nutella", de Antonio Prata, publicada na Folha de S. Paulo em 12/09/2020.

A análise de tais enunciados verbo-visuais e verbais que circulam na mídia procura demonstrar a precariedade e os conflitos motivados pela falta de um projeto político de apoio educacional que pudesse minimizar os problemas sociais e os conflitos vivenciados na rotina diária por professores, pais e alunos. As charges, por meio da sátira e do humor, expõem os problemas que subjazem no discurso e que afetam a população. A crônica de Antonio Prata coloca em evidência o conflito familiar dos pais e dos filhos diante da falta de apoio para solucionar as dificuldades enfrentadas na rotina diária. Cada um dos autores manifesta seu tom valorativo e seu posicionamento crítico diante do atual contexto sociopolítico.

Para o desenvolvimento deste artigo, discute-se a princípio, as questões relevantes a respeito da educação e das orientações dos documentos oficiais que norteiam o ensino no Brasil e, a seguir, apresenta-se a teoria que fundamenta as análises que se desenvolvem na sequência, encaminhando para as observações finais.

\section{OS DOCUMENTOS OFICIAIS E A NECESSIDADE DE NOVOS ENFOQUES DE LEITURA}

A garantia de oferta de educação está prevista na Constituição Federal de 1988, quando trata dos direitos e das garantias fundamentais, no capítulo II, Dos Direitos Sociais assim expresso em seu artigo 6․:

São direitos sociais a educação, a saúde, a alimentação, o trabalho, a moradia, o transporte, o lazer, a segurança, a previdência social, a proteção à maternidade e à infância, a assistência aos desamparados, na forma desta Constituição. (BRASIL, CF, 1988).

No capítulo III, que trata da Educação, da Cultura e do Desporto, Seção I - Da Educação, temos o artigo 205, que postula:

Art. 205. A educação, direito de todos e dever do Estado e da família, será promovida e incentivada com a colaboração da sociedade, visando ao pleno desenvolvimento da pessoa, seu preparo para o exercício da cidadania e sua qualificação para o trabalho. (IDEM)

Temos ainda, duas leis que regulamentam e complementam a do direito à Educação, qual sejam: o Estatuto da Criança e do Adolescente (ECA), de 1990; e a Lei de Diretrizes e Bases da 


\title{
RECIMA21 - REVISTA CIENTÍFICA MULTIDISCIPLINAR
}

DESAFIOS DA EDUCAÇÃo REFLETIDOS E REFRATADOS NA MÍDIA DURANTE A PANDEMIA COVID19 Sonia Sueli Berti Pinto, Miriam Bauab Puzzo

Educação (LDB), de 1996. Esses institutos jurídicos garantem ingresso na escola pública fundamental a todos os cidadãos brasileiros.

A Educação é um dever do Estado e da Família e, em conformidade com o art. 208 da CF, caput, incisos e parágrafos:

\begin{abstract}
Art. 208. O dever do Estado com a educação será efetivado mediante a garantia de: I - educação básica obrigatória e gratuita dos 4 (quatro) aos 17 (dezessete) anos de idade, assegurada inclusive sua oferta gratuita para todos os que a ela não tiveram acesso na idade própria; (...)
\end{abstract}

§ 1ㅇ $\mathrm{O}$ acesso ao ensino obrigatório e gratuito é direito público subjetivo. (BRASIL, 1988).

É por meio da Educação que se habilita o cidadão para participação efetiva na sociedade e o qualifica para 0 trabalho, possibilita que tenha ciência de seus direitos e deveres, facultando 0 exercício pleno da cidadania, direitos esses garantidos pela Carta Magna.

Durante o ano de 2020, com a pandemia do COVID-19, todos os setores do país foram afetados, dentre eles, o da Educação.

A doença obrigou governos a tomarem medidas urgentes e excepcionais no intuito de conter o alastramento da doença ${ }^{1}$, a contaminação da população, o colapso do sistema de saúde, o caos social ${ }^{2}$ e econômico ${ }^{3}$.

No Brasil, em março de 2020, foi confirmado, segundo fontes oficiais do governo, o primeiro caso de morte pelo Covid-19, e, a partir disso, medidas enfrentamento emergencial ${ }^{4}$ estão sendo tomadas na área de saúde ${ }^{5}$, de reconhecimento de calamidade pública ${ }^{6}$, de fechamento de aeroportos $^{7}$ e de isolamento social ${ }^{8}$, de fechamentos de estradas, medidas trabalhistas e educacionais, entre outras.

\footnotetext{
${ }_{1}$ Portaria no 454, de 20.3.2020, publicada no DOU de 20.3.2020 - Edição extra - F. Declara, em todo o território nacional, o estado de transmissão comunitária do coronavírus (covid-19).

2 Resolução ํo 152, de 18.3.2020, publicado no DOU de 18.03.2020 - Edição extra D. Prorroga o prazo para pagamento dos tributos federais no âmbito do Simples Nacional.

${ }^{3}$ Resolução no 1.338 , de 17.3.2020, publicado no DOU de 18.03.2020. Fixação de teto máximo de juros ao mês, para as operações de empréstimo consignado em benefício previdenciário, e dá outras providências.

4 LEI № 13.979, DE 6 DE FEVEREIRO DE 2020. Dispõe sobre as medidas para enfrentamento da emergência de saúde pública de importância internacional decorrente do coronavírus responsável pelo surto de 2019.

5 Medida Provisória no 926, de 20.3.2020, publicada no DOU de 20.3.2020 - Edição extra - G. Altera a Lei no 13.979, de 6 de fevereiro de 2020, para dispor sobre procedimentos para aquisição de bens, serviços e insumos destinados ao enfrentamento da emergência de saúde pública de importância internacional decorrente do coronavírus.

Lei $n^{0}$ 13.979, de 6.2.2020, publicada no DOU de 7.2.2020. Dispõe sobre as medidas para enfrentamento da emergência de saúde pública de importância internacional decorrente do coronavírus responsável pelo surto de 2019.

6 Decreto Legislativo oㅡ 6, de 20.3.2020, publicado no DOU de 20.3.2020 - Edição extra - C. Reconhece, para os fins do art. 65 da Lei Complementar no 101, de 4 de maio de 2000, a ocorrência do estado de calamidade pública, nos termos da solicitação do Presidente da República encaminhada por meio da Mensagem ㄲo 93, de 18 de março de 2020.

7 Portaria no 126, de 19.3.2020, publicado no DOU de 19.03.2020 - Edição extra-E e republicado no DOU de Edição extra-D.
} 


\section{RECIMA21 - REVISTA CIENTÍFICA MULTIDISCIPLINAR}

DESAFIOS DA EDUCAÇÃO REFLETIDOS E REFRATADOS NA MÍDIA DURANTE A PANDEMIA COVID19 Sonia Sueli Berti Pinto, Miriam Bauab Puzzo

Nestes tempos de pandemia, com a questão do contágio, da necessidade de afastamento social, de medidas protetivas, a oferta educacional necessita ser garantida por decretos e leis que possibilitem essa oferta de educação de qualidade, um dos pilares da sociedade contemporânea, garantida nos diversos diplomas legais.

Imbrica-se a educação de qualidade à dignidade do ser humano, motivo pelo qual as normas, decretos e leis visam à diminuição de desigualdades, ao desenvolvimento social, à garantia da cidadania plena e à preservação da vida, conforme aponta-nos Piovesan ${ }^{9}$ :

$[\ldots]$

A dignidade da pessoa humana, (...) está erigida como princípio matriz da Constituição, imprimindo-lhe unidade de sentido, condicionando a interpretação das suas normas e revelando-se, ao lado dos Direitos e Garantias Fundamentais, como cânone constitucional que incorpora as exigências de justiça e dos valores éticos, conferindo suporte axiológico a todo o sistema jurídico brasileiro. (PIOVESAN, 2000, p. 54)

Essas questões impactaram no modo de o mundo se relacionar com questões trabalhistas, humanas, sociais, econômicas e educacionais. Desde então, uma nova ordem social vem se desenhando, afetando a área educacional, com aumento da interação por meios eletrônicos e remotos.

Para garantia da dignidade da pessoa humana e da oferta de educação de qualidade, o Ministério da Educação - MEC, a partir da Lei № 13.979, de 06 de fevereiro de 2020, publica várias Portarias que visam garantir que estudantes de todo o país tenham acesso à educação por meios eletrônicos e de modo remoto em período de isolamento social, em meio a pandemia do Covid-19.

Atualmente, está em vigor a Portaria MEC № $1.038^{10}$, de 07 de dezembro de 2020 , que altera a Portaria MEC no 544, de 16 de junho de 2020, que dispõe sobre a substituição das aulas presenciais por aulas em meio digitais, enquanto durar a situação de pandemia do novo coronavírus - Covid-19, e a Portaria MEC no 1.030 , de 1ํ de dezembro de 2020, que dispõe sobre o retorno às aulas presenciais e sobre caráter excepcional de utilização de recursos educacionais digitais para integralização da carga horária das atividades pedagógicas, enquanto durar a situação de pandemia do novo coronavírus - Covid-19.

A Portaria $n^{0} 343$, de 17 de março de $2020^{11}$, já dispunha sobre a questão de oferta de aulas remotas, em meio eletrônico em substituição das aulas presenciais pelo período de trinta dias,

PORTARIA № 518, DE 12 DE NOVEMBRO DE 2020, publicado em: 12/11/2020, Edição: 216-A, Seção: 1, Extra A, Página: 1. Órgão: Presidência da República/Casa Civil. Dispõe sobre a restrição excepcional e temporária de entrada no País de estrangeiros, de qualquer nacionalidade, conforme recomendação da Agência Nacional de Vigilância Sanitária - Anvisa. https://www.in.gov.br/en/web/dou/-/portaria-n-518-de-12-de-novembro-de-2020288022437

8 Portaria no 356/3020, que regulamenta as medidas para o enfrentamento da emergência de saúde pública de importância internacional em decorrência do coronavírus (Covid-9). A medida regulamenta a Lei 13.979/20.

9 PIOVESAN, Flávia. Direitos humanos e o direito constitucional internacional. 4ed. São Paulo: Max Limonad, 2000, p. 54

10 Portaria MEC № 1.038, de 07 de dezembro de 2020 . Disponível em: https://abmes.org.br/arquivos/legislacoes/Portaria-mec-1038-2020-12-07.pdf. Último acesso em 10/02/2021.

11 Portaria no 343, de 17 de março de 2020. Dispõe sobre a substituição das aulas presenciais por aulas em meios digitais enquanto durar a situação de pandemia do Novo Coronavírus - COVID-19. Disponível em: 


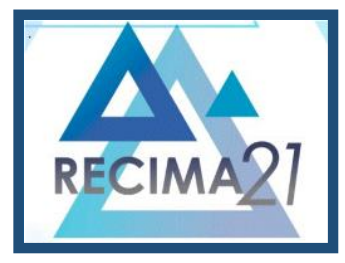

\section{RECIMA21 - REVISTA CIENTÍFICA MULTIDISCIPLINAR}

DESAFIOS DA EDUCAÇÃo REFLETIDOS E REFRATADOS NA MÍDIA DURANTE A PANDEMIA COVID19 Sonia Sueli Berti Pinto, Miriam Bauab Puzzo

podendo ser prorrogável. O que não se esperava era que essa pandemia durasse tanto e nem que pudesse ser agravada, como vemos agora, neste início de 2021.

Muitos foram os problemas gerados na área educacional, pelo advento dessa pandemia. Entre eles, a necessidade urgente de as instituições de ensino tanto da Educação Básica quanto da Superior subitamente virem-se obrigadas a ofertar aulas remotas com o uso de tecnologias digitais.

A educação básica é formada por três grandes etapas: educação infantil, ensino fundamental e médio. De acordo com a Lei de Diretrizes e Bases da Educação Nacional, Lei № 9.394/96, o Estado tem o dever de ofertar educação básica obrigatória e gratuita dos 4 (quatro) aos 17 (dezessete) anos de idade. À iniciativa privada o ensino é livre desde que atendidas as condições estabelecidas na legislação. Até 2017, somente instituições de ensino superior devidamente credenciadas pelo MEC podiam ofertar aulas não presenciais - a educação a distância - EaD. Embora prevista a possibilidade de oferta de EaD para a educação básica, isso não ocorria no país.

Repentinamente, a educação básica encara a premência dessa oferta, sem meios tecnológicos, sem recursos materiais nem humanos capacitados para essa oferta.

Embora na BNCC - Base Nacional Comum Curricular (BNCC) $)^{12}$ que é um documento criado para nortear educadores e instituições de ensino sobre os conhecimentos considerados essenciais e indispensáveis ao desenvolvimento das crianças e jovens, proponha estratégias, conceitos e situações a serem ser trabalhadas em cada fase da educação básica, entre as competências definidas para assegurar no, âmbito pedagógico, os direitos de aprendizagem e desenvolvimento, temos assim expresso na Competência 5 (pg. 11):

Compreender, utilizar e criar tecnologias digitais de informação e comunicação de forma crítica, significativa, reflexiva e ética nas diversas práticas sociais (incluindo as escolares) para se comunicar, acessar e disseminar informações, produzir conhecimentos, resolver problemas e exercer protagonismo e autoria na vida pessoal e coletiva. (BNCC, 2018, p. 11)

Apesar de as Leis e Diretrizes já indicarem a necessidade de se preparar o educando para as tecnologias digitais e de as instituições trabalharem com essa modalidade, evidencia-se, com a pandemia e a necessidade de se trabalhar de modo remoto, o despreparo de muitas instituições de ensino públicas e privadas, bem como de seus professores e coordenadores. Isso evidencia o despreparo de docentes utilizarem as TICs em suas atividades diárias e, assim, conduzirem seus educandos para um mundo mais tecnológico, em que as TICs são presença obrigatória.

Houve, então uma corrida para essa oferta por parte das instituições na tentativa de sanar as deficiências tanto de insumos materiais quanto na capacitação dos docentes e, também, em

https://www.in.gov.br/en/web/dou/-/portaria-n-343-de-17-de-marco-de-2020-248564376. Último acesso em 15/01/2021.

12 BRASIL Ministério da Educação. Base Nacional Comum Curricular. Brasília, 2018. Regra Geral. (BNCC). Disponível em: http://basenacionalcomum.mec.gov.br/images/BNCC_El_EF_110518_versaofinal_site.pdf. Último acesso em 10/02/2021. 


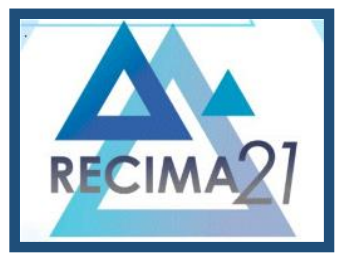

\section{RECIMA21 - REVISTA CIENTÍFICA MULTIDISCIPLINAR}

DESAFIOS DA EDUCAÇÃo REFLETIDOS E REFRATADOS NA MÍDIA DURANTE A PANDEMIA COVID19 Sonia Sueli Berti Pinto, Miriam Bauab Puzzo

estabelecer estratégias para que esse ensino, até então, inusitado para e educação básica, fosse ofertado de modo minimamente eficiente.

Evidenciou-se a mobilização dos docentes que se viram obrigados a trabalhar de casa, usar de recursos próprios, criar metodologias e rotinas para conseguirem ministrar aulas capazes de transmitir o conteúdo e garantir que a atenção do aluno se mantivesse durante toda a aula.

Além desses problemas, o que se evidenciou foi a redução significativa no número de matrículas de alunos na educação infantil em todo o Brasil, apresentando queda de 7,1\% na rede privada no ano de 2020, segundo apontou o Censo Escolar da Educação Básica 2020, divulgado em 29/01/2021, pelo Inep (Instituto Nacional de Estudos e Pesquisas Educacionais Anísio Teixeira) ${ }^{13}$.

Segundo o portal Todos pela Educação no Brasil, 67\% dos domicílios possuem acesso à internet, desses, $99 \%$ são da classe A, $94 \%$ da B, $76 \%$ da C e $40 \%$ da DE. Somente em $42 \%$ (47\% na classe $C$ e $9 \%$ na $D E$ ) possuem computador em casa. Fator esse que implica na quebra da questão constitucional de garantia da dignidade da pessoa humana e da oferta de educação de qualidade.

Outra questão muito importante sobre o ensino remoto refere-se ao agravamento das desigualdades socioculturais, econômicas e étnicas, o que reflete diretamente na reprovação, distorção idade-série e abandono escolar ${ }^{14}$.

Essas questões criam maior desnível no aprendizado, uma vez que, assim como instituições de ensino não estão equipadas adequadamente para oferta de ensino remoto, nem preparadas pedagogicamente para essa oferta, muitos lares também não estão.

Segundo o Programa das Nações Unidas para o Desenvolvimento - Pnud, o Brasil figura entre os países com maior desigualdade no mundo, em sétimo lugar, Brasil é o sétimo país mais desigual do mundo, segundo o último relatório divulgado pelo Pnud ${ }^{15}$ (Programa das Nações Unidas para o Desenvolvimento) em dezembro de 2019. Por este motivo, um significativo recorte de classe social ocorre no aproveitamento das aulas online.

Outro ponto que afeta significativamente essa forma de ensino por meios tecnológicos é a questão da conectividade e da qualidade da oferta de conexão com a internet, tanto pelo poder aquisitivo de se contratar um serviço de qualidade com mais megas, quanto das dificuldades técnicas que algumas regiões do país apresentam em relação às operadoras e seus serviços disponíveis.

O estudo da UNICEF, realizado em janeiro de 2021, analisa dados da Pesquisa Nacional por Amostra de Domicílios (Pnad), do Instituto Brasileiro de Geografia e Estatística (IBGE), e indica que

13 INEP. CENSO DA EDUCAÇÃO BÁSICA 2020. Disponível em:

https://download.inep.gov.br/publicacoes/institucionais/estatisticas_e_indicadores/notas_estatisticas_censo_esc olar_2020.pdf. Último acesso em 20/02/2021.

14 UNNICEF. https://www.unicef.org/brazil/comunicados-de-imprensa/cultura-do-fracasso-escolar-afeta-milhoesde-estudantes-e-desigualdade-se-agrava-na-

pandemia\#: : :text=Estudo\%20mostra\%20que\%20reprova\%C3\%A7\%C3\%A30\%2C\%20abandono,desafios\%20s e\%20tornam\%20ainda\%20maiores\&text=Sem\%20oportunidades\%20de\%20aprender\%2C\%20o,a\%20deixar\%2 Odefinitivamente\%20a\%20escola. Último acesso em 20/02/2021.

15 Pnud - Programa das Nações Unidas para o Desenvolvimento. Disponível em: https://www.br.undp.org/content/brazil/pt/home/library/relatorio-anual-2019.html. Último acesso em 20/02/2021. 


\section{RECIMA21 - REVISTA CIENTÍFICA MULTIDISCIPLINAR}

DESAFIOS DA EDUCAÇÃo REFLETIDOS E REFRATADOS NA MÍDIA DURANTE A PANDEMIA COVID19 Sonia Sueli Berti Pinto, Miriam Bauab Puzzo

1,38 milhão de estudantes de 6 a 17 anos, ou 3,8\% do total, não participaram de aulas presenciais ou remotas em outubro de 2020. Mais de 4,12 milhões relataram não ter tido acesso às atividades escolares, indicando que cerca de 5,5 milhões de crianças e adolescentes tiveram seu direito à educação negado em 2020", afirma a pesquisa ${ }^{16}$.

A pandemia também alterou os padrões das rotinas diárias das famílias que se viram, em muitos casos, com os pais em trabalho remoto e os filhos com aulas remotas, todos em casa. Esses fatores geraram inúmeras dificuldades de diversas ordens: financeiras, emocionais, de relacionamentos, de estratégias de organização de tarefas, e, também, de agravamento do número de registros de casos de violência doméstica ${ }^{17}$.

A participação e apoio dos pais nas aulas remotas síncronas é fundamental para assegurar que se garanta a base para o aprendizado, uma vez que, ou pela idade, ou pela falta de experiência nessa modalidade de ensino, muitos estudantes apresentam deficiência na habilidade de estudo de modo independente, necessitando da assistência dos pais.

O problema maior que se apresenta em relação ao estudo remoto, principalmente das séries iniciais, momento em que as crianças estão sendo alfabetizadas ${ }^{18}$, é a falta de capacidade de os docentes dessas séries iniciais estarem habituados ao ensino em meio midiáticos, que a escola tenha uma metodologia pedagógica eficiente e capaz de orientar seus professores e acompanhar as aulas e como são ministradas pedagogicamente. Dessa forma, que seja capaz de garantir que a aprendizagem se efetive.

Muito se tem relatado sobre a dificuldade de as crianças acompanharem as aulas de modo remoto, e precisarem de assistência dos pais, que ou estão trabalhando de modo remoto, ou não têm capacidade, nem habilidade para esse acompanhamento.

No caso de letramento das séries iniciais, os pais têm feito o papel da professora em casa, mas nem sempre com a formação ou competência para isso, o que pode gerar déficit de aprendizagem e de cognição nessas crianças. Problema esse que ultrapassa os limites da escola e se reflete na formação do cidadão e no desenvolvimento do país.

Há, evidentemente, pontos positivos ${ }^{19}$ na oferta de aulas remotas síncronas, uma vez que essas imprimiram novas dinâmicas, novas formas de interação, de leituras de elementos verbovisuais-sonoros. Há a possibilidade em tempo real de apresentar textos, conteúdos, trazer depoimentos, imagens de sites que enriquecem as aulas e podem ser elementos motivadores para a

\footnotetext{
$16 \mathrm{https}$ ://noticias.r7.com/educacao/unicef-55-milhoes-estavam-sem-atividades-escolares-em-outubro-28012021. 17 Violência doméstica em tempos de confinamento obrigatório: a epidemia dentro da pandemia. Disponível em: https://jus.com.br/artigos/85555/violencia-domestica-em-tempos-de-confinamento-obrigatorio. Acesso em 20/02/2021.

18 Como superar os desafios da alfabetização e do letramento em tempos de ensino remoto. Disponível em: https://desafiosdaeducacao.grupoa.com.br/desafios-alfabetizacao-ensino-remoto/. Acesso em 20/02/2021.

19 Instituto Federal de Educação, Ciência e Tecnologia do Ceará. IFCE. MINISTÉRIO DA EDUCAÇÃO: Alunos e docentes avaliam ensino remoto na prática. Disponível em: https://ifce.edu.br/noticias/alunos-e-docentesavaliam-ensino-remoto-na-pratica. Acesso em 20/02/2021.
} 


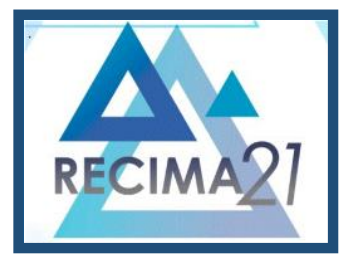

\section{RECIMA21 - REVISTA CIENTÍFICA MULTIDISCIPLINAR}

DESAFIOS DA EDUCAÇÃo REFLETIDOS E REFRATADOS NA MÍDIA DURANTE A PANDEMIA COVID19 Sonia Sueli Berti Pinto, Miriam Bauab Puzzo

retenção dos alunos nas aulas. Evidencia-se, desse modo, a necessidade de docentes e estudantes terem domínio de leitura de diversas linguagens para sua formação.

A necessidade de estabelecer estratégias de ensino/aprendizagem considerando essas diversas linguagens e meios tecnológicos de ensino é de suma importância no atual cenário.

\section{ALGUMAS INFORMAÇÕES TEÓRICAS}

A concepção de linguagem de Bakhtin e o Círculo possibilitou a compreensão do processo de comunicação de modo mais abrangente, ampliando o horizonte interpretativo de textos na perspectiva discursiva. O conceito de enunciado, enunciação e enunciado concreto não se diferenciam e são usados como equivalentes para Bakhtin porque fazem parte do processo comunicativo e são considerados uma unidade enunciativa resultante da relação triádica: enunciador, destinatário e contexto social, conforme pontua Bakhtin (2016). Portanto, o enunciado não se reduz à sua materialidade textual, embora esta o constitua. Nas palavras de Bakhtin (2016, p.28), "o discurso só pode existir de fato na forma de enunciados concretos de determinados falantes, sujeitos do discurso". Sob esse aspecto, o enunciado concreto se constitui por meio de gêneros discursivos, pois para Bakhtin (2016) toda forma de comunicação se realiza em gêneros que são formas mais ou menos estáveis que permitem a comunicação entre os seres humanos. De acordo com sua teoria,

\footnotetext{
Falamos apenas através de certos gêneros do discurso, isto é, todos os nossos enunciados têm formas relativamente estáveis e típicas de construção do conjunto. Dispomos de um rico repertório de gêneros de discurso orais (e escritos). (BAKHTIN, 2016, p.38)
}

Sob essa perspectiva, desde um simples cumprimento até um romance são concebidos em forma de gêneros discursivos. Assim, tanto uma crônica publicada em jornal como as charges que ilustram humoristicamente uma revista são gêneros discursivos passíveis de serem interpretados sob a ótica bakhtiniana. A seus elementos essenciais como o tema, a forma composicional e o estilo que o caracterizam, são acrescidos outros elementos também constitutivos, entre eles o posicionamento valorativo do sujeito e seu estilo individual decorrente de sua proposta comunicativa. Nessa perspectiva, os gêneros tornam-se mais complexos, compreendidos como respostas de seus enunciadores ao contexto imediato, relacionando seu posicionamento valorativo e sua responsabilidade como enunciador. Por outro lado, o enunciado, uma vez verbalizado, aguarda atitudes responsivas dos possíveis destinatários, ainda que tais respostas não sejam explicitamente verbalizadas. Como concebe o autor:

O falante termina seu enunciado para passar a palavra ao outro ou dar lugar à sua compreensão ativamente responsiva. O enunciado não é uma a unidade convencional, mas uma unidade real, delimitada com precisão pela alternância dos sujeitos do discurso e que termina com a transmissão da palavra ao outro, por mais silencioso que seja o "dixit" percebido pelos ouvintes [como sinal] que o falante concluiu sua fala. (BAKHTIN, 2016, p.29) 


\section{RECIMA21 - REVISTA CIENTÍFICA MULTIDISCIPLINAR}

DESAFIOS DA EDUCAÇÃo REFLETIDOS E REFRATADOS NA MÍDIA DURANTE A PANDEMIA COVID19 Sonia Sueli Berti Pinto, Miriam Bauab Puzzo

Portanto, o enunciado não se reduz a ele mesmo como uma unidade específica da língua. Sua conclusibilidade relativa só se completa com as respostas efetivas de seus destinatários ou possíveis leitores. Concebido dessa forma, o enunciado concreto estabelece relações dialógicas tanto com o outro a que se destina, quanto com o contexto social em que foi elaborado.

Entretanto, como um gênero discursivo que se submete às regularidades específicas de cada gênero, o enunciado concreto também evidencia peculiaridades próprias de seus enunciadores, principalmente os gêneros mais propícios à inflexão do autor. Nesse caso, o estilo individual interfere na concretização de tais gêneros, colocando em evidência a proposta comunicativa do autor e seu tom valorativo, explicitando sua visão de mundo.

Desse modo, os enunciados integrados à cadeia discursiva tornam-se elos propiciadores de múltiplas atitudes responsivas em função do lugar situado em que se encontram seus destinatários. Sob esse aspecto, a crônica e as charges selecionadas explicitam os problemas vivenciados no contexto social imediato como respostas de seus autores às condições sociopolíticas desse contexto e ao mesmo tempo suscitam atitudes responsivas de seus leitores. Portanto, seus enunciadores, ao se expressarem, posicionam-se responsavelmente como sujeitos sociais diante dos conflitos vivenciados no cotidiano.

De acordo com Bakhtin, o enunciador em sua função social é responsável por seus atos, sejam eles expressos por meio de palavras, ou outras formas de expressão, constituídas por material sígnico, tais como gestos, mímica, desenhos etc. O signo, sob esse aspecto, expressa valores, pontos de vista, visão de mundo de seus enunciadores. Na concepção de Volóchinov (2017, p.94), o signo é ideológico porque reflete e refrata a realidade. Em suas palavras, "o signo não é somente uma parte da realidade, mas também reflete e refrata outra realidade, sendo por isso capaz de distorcê-la, ser-lhe fiel, percebê-la de um ponto de vista específico e assim por diante." (VOLÓCHINOV, 2017, p.92).

\footnotetext{
Qualquer signo ideológico é não apenas um reflexo, uma sombra da realidade, mas também uma parte material dessa mesma realidade. Qualquer fenômeno ideológico sígnico é dado em algum material: no som, na massa física, na cor, no movimento do corpo e assim por diante. (VOLÓCHINOV, 2017, p.94)
}

Sob esse prisma, o signo ideológico evidencia valores, visão de mundo, posicionamentos axiológicos de seus enunciadores. Assim, nessa concepção, o enunciador assume um papel responsável por aquilo que expressa, expondo seu ponto de vista. Como o enunciador também responde, ele assume uma posição responsível, ou seja, o ser humano é responsável por seus atos, respondendo ao contexto imediato em que se encontra situado. Como se manifesta Sobral (2005, p.111): "segundo Bakhtin, a vida dos seres humanos (que não têm álibi na existência) define-se como uma sequência de atos éticos, responsáveis e responsivos."

Nessa perspectiva, toda ação humana é um ato em resposta ao contexto, do qual o indivíduo se torna responsável. Ao se manifestar por meio de enunciados que circulam no meio social, o enunciador assume sua responsabilidade. Portanto, ao escrever ou produzir textos na mídia, o 


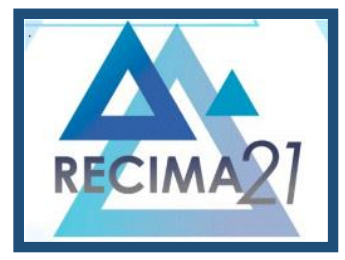

\section{RECIMA21 - REVISTA CIENTÍFICA MULTIDISCIPLINAR}

DESAFIOS DA EDUCAÇÃo REFLETIDOS E REFRATADOS NA MÍDIA DURANTE A PANDEMIA COVID19 Sonia Sueli Berti Pinto, Miriam Bauab Puzzo

sujeito/autor responde aos enunciados anteriores e assume seu posicionamento valorativo diante deles, aguardando respostas ativas do público leitor, como é o caso de Antônio Prata, autor da crônica selecionada e do chargista Caco Galhardo responsável pelas charges da revista Piauí, selecionadas para análise.

Nesse caso, além de expressarem seus pontos de vista numa perspectiva ética como mediadores sociais, também trabalham o estilo próprio na composição de seus enunciados. Sob esse aspecto, Sobral (2010) discute a relação entre ética e estética proposta por Bakhtin, como intrínsecas ao ato de produção literária, que ainda é pouco explorado. Com apoio dessa perspectiva, considera-se que o aspecto expressivo em gêneros mais permeáveis à inserção autoral, demonstra essa relação entre o posicionamento valorativo e ético dos enunciadores com sua forma expressiva, ou seja, estética. Portanto, ao se expressarem explorando os recursos linguísticos para cumprir suas propostas comunicativas também se manifestam eticamente expondo seu tom avaliativo como sujeitos situados. Enquanto a crônica se constitui pela linguagem verbal, as charges se caracterizam pela articulação verbo-visual, criando efeitos humorísticos e satíricos.

Embora, Bakhtin e o Círculo tenham se debruçado sobre a linguagem verbal, os autores sinalizaram a possibilidade de comunicação por signos dos mais diferentes meios expressivos. Sendo assim, na interpretação da verbo-visualidade dessas charges, consideram-se todos os elementos de sua composição, cores, traços, disposição na página, diagramação como partes significativas na composição da unidade temática de cada uma delas, como aponta Dondis (2003) ao tratar da sintaxe visual. Segue-se, também, a concepção de Brait explicitada em Literatura e outras linguagens (2010) de que os enunciados compostos por signos verbais e visuais devem ser considerados em sua unidade verbo-visual, convergindo para os efeitos de sentido do enunciado de acordo com o tema que o organiza.

\section{DAS ANÁLISES}

\subsection{ANÁLISE DA CRÔNICA "Tela, cautela, nutella"}

O título dessa crônica, "Tela, cautela, nutella" de Antonio Prata, publicada na llustrada da Folha de S, Paulo, é bastante sugestivo no momento atual, associa elementos aparentemente díspares, mas que se encontram presentes no contexto familiar imposto pela pandemia do Covid19. As famílias isoladas no ambiente doméstico, trabalhando em home-office, em convivência permanente com seus filhos, que também estão isolados assistindo aulas virtuais. Os pais tornam-se, de repente, inteiramente responsáveis pelo trabalho executado em casa e pelo cuidado com os filhos, anteriormente partilhado com a escola, onde as crianças passavam grande parte do tempo. $O$ cenário doméstico transformou-se, criando atritos entre seus membros. Como o autor se manifesta no início sua crônica:

Queridos pais e mães. Não sei se já falaram disso aqui no grupo: como é que seus filhos tão lidando com o ensino remoto? Os meus tão muito ansiosos, não querem fazer, choram... Tô em dúvida se insisto, se desencano do homeschooling ou se 


\section{RECIMA21 - REVISTA CIENTÍFICA MULTIDISCIPLINAR}

DESAFIOS DA EDUCAÇÃo REFLETIDOS E REFRATADOS NA MÍDIA DURANTE A PANDEMIA COVID19 Sonia Sueli Berti Pinto, Miriam Bauab Puzzo

desencano do meu emprego e fico todas as tardes ao lado deles, ajudando. Digam lá. (PRATA, 2020)

Já neste fragmento é possível perceber que o autor questiona se outros núcleos familiares passam pela mesma situação. Valendo-se de uma linguagem informal, seus questionamentos refletem sua angústia em busca de respostas: "e comecei a me perguntar se forçá-los a serem cobaias, com tanto sofrimento, neste experimento social, não era como submetê-los a uma espécie de cloroquina pedagógica antes de termos estudos confiáveis sobre os efeitos adversos."

Os conflitos com as crianças são potencializados pelo autor ao citar os atritos entre os casais que não estão habituados a conviver enclausurados num mesmo ambiente, de modo a desempenhar vários papéis: como pais, trabalhadores, funcionários, professores e parceiros na vida em comum. Como explicita:

(Eu e a minha mulher já brigamos algumas vezes. Ela tem certeza de que eu acordo de madrugada só pra esconder o jogo da memória de fundo do mar no meio das fichas de alfabetização, mas eu sei que é ela quem tenta me enlouquecer moqueando a ficha das cores em inglês no meio da pasta de matemática).

Os conflitos se desenvolvem de modo traumático entre os membros da família, provocando um clima de desconfiança, de cobrança e de interesses conflitantes. O peso dessa responsabilidade também se estende às escolas e aos profissionais da educação e, na opinião do autor, a situação inédita não encontra respaldo em projetos públicos consistentes para lidar com os problemas.

Estamos vivendo um estado de exceção. Ninguém tem fórmula para a retomada da economia, a sobrevivência dos casamentos, para os lutos sem velórios ou sequer para a prática de atividades físicas ao ar livre. É bom expormos as crianças às aulas on-line com bastante cautela -e se mesmo a cautela for inútil contra o sofrimento, talvez não seja de todo o mal apelarmos para a Nutella.

Com certo humor, o autor procura aliviar a tensão familiar em que se encontra, expondo o conflito social vivenciado pela falta de perspectivas que as famílias enfrentam, sem nenhum vislumbre de apoio institucional, com projetos para amenizar a insegurança e a improvisação educacional.

\subsection{ANÁLISE DAS CHARGES DA REVISTA PIAUÍ}

As charges da revista Piauí, de Caco Galhardo, publicadas pela Revista Piauí, ㄲo164, 2020, tocam em questões fundamentais que afetam a sociedade brasileira pela ausência de uma condução governamental mais transparente e afinada com propostas de solução emergencial de problemas, como se verifica na administração governamental da epidemia da Covid19. A necessidade de isolamento social no combate ao vírus, a mudança de hábitos exigidos pelo trabalho at home e as aulas virtuais, exigiam um projeto que procurasse atender as necessidades impostas pelo novo formato do ensino a distância. Entretanto, os problemas educacionais ficaram à deriva pela falta de dirigentes competentes no ministério da educação. Portanto, as três charges selecionadas tratam de num aspecto fundamental que motivou o tema da crônica, ou seja, a ausência de uma orientação pontual oferecida pelo governo para apresentar alternativas ou soluções improvisadas para a 


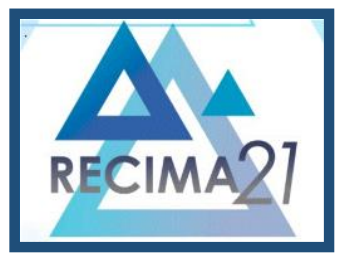

\section{RECIMA21 - REVISTA CIENTÍFICA MULTIDISCIPLINAR}

DESAFIOS DA EDUCAÇÃo REFLETIDOS E REFRATADOS NA MÍDIA DURANTE A PANDEMIA COVID19 Sonia Sueli Berti Pinto, Miriam Bauab Puzzo

educação nesse momento. As escolas foram obrigadas a improvisar, exigindo dos professores atuação virtual sem nenhum preparo para exercer essa função. Caco Galhardo, por meio das charges, expõe a falta de capacidade do Ministério de Educação apresentar um projeto consistente para esse momento.

A primeira charge expõe de modo ridículo o discurso oficial, que o título anuncia: "Como não administrar uma pandemia" redigido em letras garrafais em negrito sobre o fundo bege. As cores que compõem o texto são neutras variando entre o preto o bege e o areia. A proposta do curso anunciada: "Curso presencial com especialista no assunto. Grátis" foi estrategicamente distribuída no espaço textual com destaque para CURSO GRÁTIS, com tipos preenchidos por marrom circundados pelo preto, Presencial e especialista em tipos menores em negrito e "com", "no assunto" sem destaque, finalizando com a informação, como se fosse um lembrete, no pé da página sobre fundo branco: "vagas ilimitadas". A imagem completa o enunciado: sob o holofote, um palestrante bem vestido com uma faixa sobre o peito e um rosto risonho emite sons sem sentido diante do microfone. A faixa é significativa, aludindo à figura presidencial que aparentemente se manifesta sobre temas sem nenhuma compreensão real do assunto como se fosse um especialista. $O$ tom mordaz da crítica é uma resposta do enunciador diante da falta de competência e de gerenciamento dos problemas enfrentados pela população do país

O conjunto expõe a situação precária dos responsáveis pela administração do ensino no país. As crônicas de Galhardo colocam em evidência esse contexto ao apresentar pessoas sem nenhum conhecimento como se fossem especialistas, ludibriando a plateia. Estabelece desse modo relações dialógicas com o contexto imediato, instigando atitudes responsivas em relação à incapacidade, falta de habilidade, incompetência dos dirigentes do país em relação às questões da pandemia.

As escolhas das unidades discursivas reiteram a postura axiológica do autor-criador em relação ao governo e à figura do presidente e suas ações.

No título a negativa "não administrar", depois "curso presencial", "vagas ilimitadas", "com

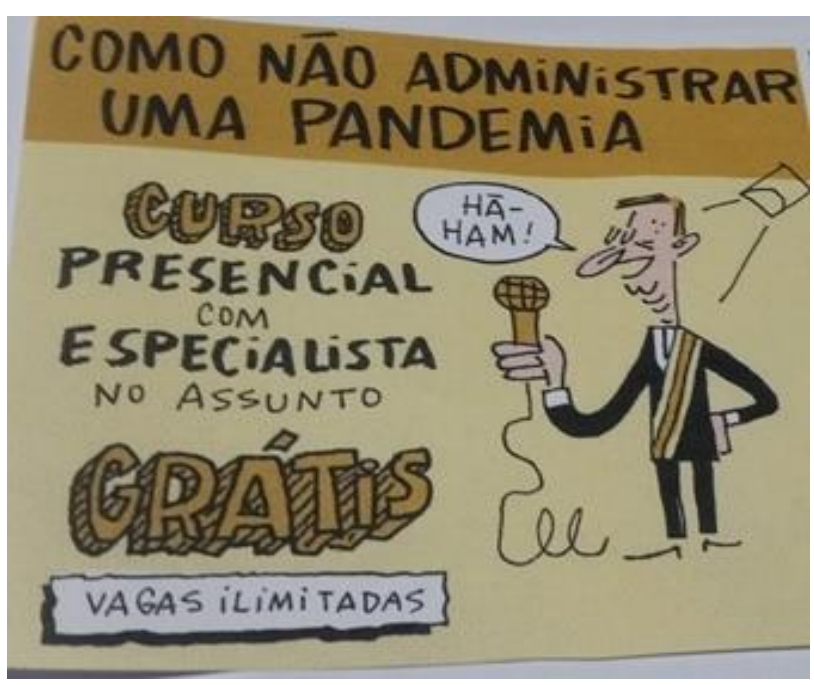
especialista", "curso grátis", "vagas ilimitadas", todas essas escolhas evidenciam a palavra viva do enunciador, refletindo sua linguagem interior, sua axiologia, conscientemente a sua linguagem interna está refletindo e fazendo refratar sua consciência sobre o fato, sobre o momento e sobre as ações, omissões do governo do presidente. (VOLOSHINÓV/BAJTIN, 1998, p. 39)

O enunciador apresenta sua crítica 


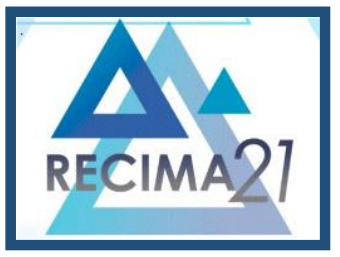

\section{RECIMA21 - REVISTA CIENTÍFICA MULTIDISCIPLINAR}

DESAFIOS DA EDUCAÇÃo REFLETIDOS E REFRATADOS NA MÍDIA DURANTE A PANDEMIA COVID19 Sonia Sueli Berti Pinto, Miriam Bauab Puzzo

sobre a (não) atuação do Presidente na administração da pandemia, indicando inclusive a "especialidade" do mesmo em não-administrar. A oferta de um curso com "vagas ilimitadas" sugere que a "metodologia" deve ser inclusive distribuída. O enunciador deixa claro seu entendimento sobre o governo e o presidente que não sabem administrar, são especialistas em não-administrar e, ainda, distribuem de graça essa incompetência.

Às incoerências marcadas pela negativa não administrar, vagas ilimitadas em cursos presenciais gratuitos subjaz o tom valorativo do enunciador, visando estabelecer, relações dialógicas com os discursos internos de seus leitores presumidos em relação à administração e condução do presidente de ações em relação à pandemia. Por meio do humor o chargista expressa sua crítica dura em relação a esse contexto.

A segunda charge dá sequência a essa perspectiva de engodo na emergência de representantes públicos sem preparo efetivo sobre os assuntos tratados.

A imagem representativa de um

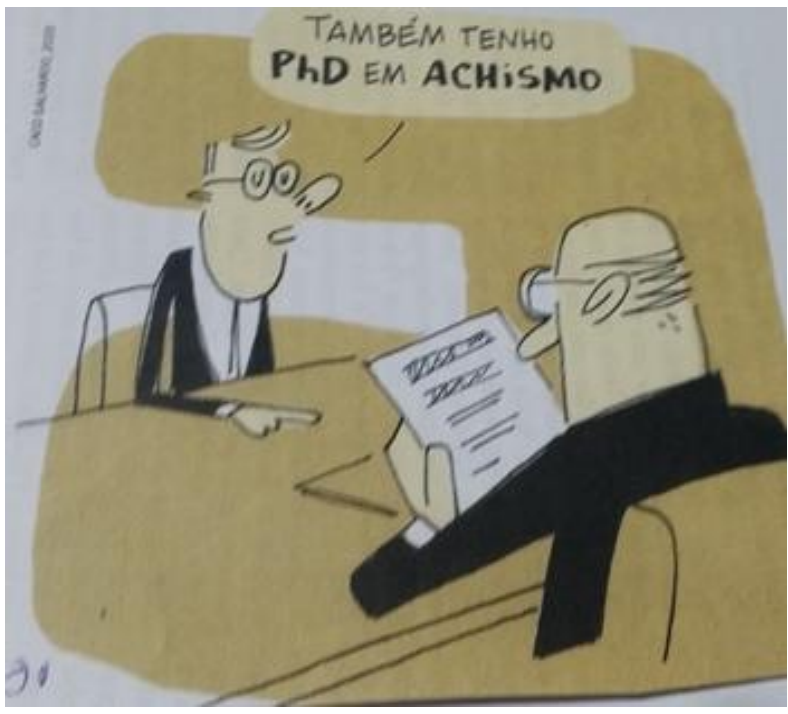
entrevistador e de um candidato pleiteando uma vaga faz alusão direta a essa falta de responsabilidade ao pleitear ou assumir cargos sem a devida formação.

A fala do candidato remete a discursos que circularam amplamente nas mídias sobre a posse de pessoas a cargos na área da saúde e educação, cujos currícula os apresentava como doutores, PHD, com mestrado, doutorado e mesmo pós-doutorado em universidades tanto brasileiras quanto estrangeiras. Posteriormente foram desmascarados pelas próprias entidades que vieram a público esclarecer que os tais candidatos, ou mesmo empossados não haviam feito os cursos que alegavam ter feito. Vale lembrar que fazer afirmações falsas no Curriculum Lattes é crime, caracterizando falsidade ideológica.

Subjacente a esse discurso está a postura axiológica do enunciador que deixa subentendida a crítica ao governo e, por conseguinte, ao Presidente, pela falta de competência em escolher nomes idôneos para cargos de tamanha importância no contexto da pandemia. As escolhas éticas e estéticas do enunciador, conforme discute Bajtin (1997), que se expressa por meio das formas, imagens e palavras deixam transparecer o sujeito/autor que responsivelmente responde aos enunciados anteriores das mídias veiculadas e assume a responsabilidade sobre seu posicionamento valorativo diante deles, advinda das possíveis atitudes responsivas do público leitor. Assim, a conclusibilidade relativa do enunciado concreto só se efetiva a partir das atitudes responsivas dos leitores presumidos, estabelecendo com o contexto social em que se encerram relações dialógicas. 


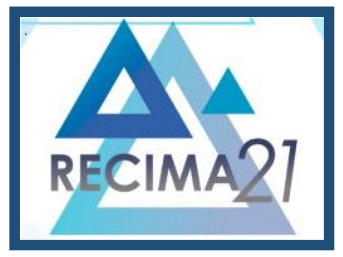

\section{RECIMA21 - REVISTA CIENTÍFICA MULTIDISCIPLINAR}

DESAFIOS DA EDUCAÇÃo REFLETIDOS E REFRATADOS NA MÍDIA DURANTE A PANDEMIA COVID19 Sonia Sueli Berti Pinto, Miriam Bauab Puzzo

A terceira charge, por meios de elementos pressupostos e implícitos, aciona a memória discursiva do leitor presumido. Há uma crítica velada à figura do Presidente da República, representado de modo caricaturado, e uma alusão à sua capacidade de usar subterfúgios como recurso para evitar o enfrentamento do problema real da pandemia.

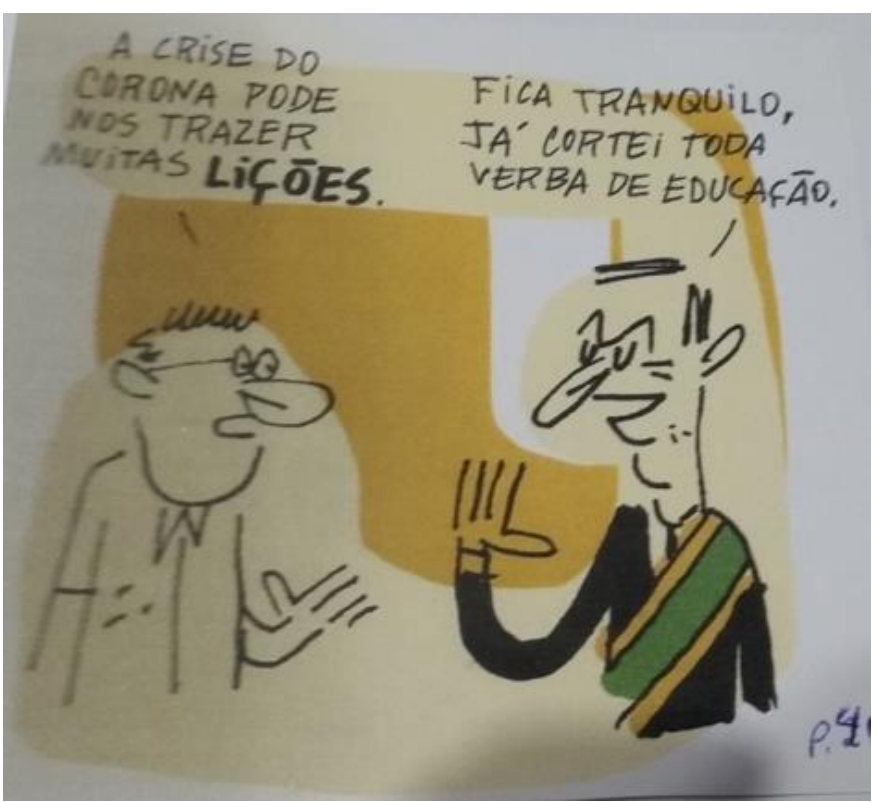

No primeiro balão, a unidade discursiva lições, aparece grafada em negrito na fala do interlocutor do Presidente. Axiologicamente 0 autor-criador do enunciado verbo-visual busca estabelecer relações dialógicas com o leitor presumido, por meio da fala do Presidente, evidenciando que não entende o que seu interlocutor diz. $\mathrm{Na}$ fala: Fica tranquilo o tom valorativo das escolhas ética $\mathrm{e}$ estéticas das unidades discursivas indica a crítica à percepção e cognição do presidente ao relacionar o termo "lições" aos seus interesses de cortar 0 investimento em educação. O verbo no imperativo evidencia a autoridade e o predicativo visa a acalmar o outro. Na segunda parte da fala do presidente, o autor-criador deixa explicitamente evidenciada a ação em relação à educação, com o verbo cortar no pretérito perfeito, ou seja, uma ação já finalizada, de cortar toda a verba da educação. Implicitamente, busca estabelecer relações dialógicas com o leitor presumido de modo que ele busque em suas memórias discursivas o entendimento de que por ter cortado toda a verba para a educação, o país não formará sujeitos capazes de leituras responsáveis e responsíveis, do mesmo modo que o presidente não entende o valor ético da escolha estética da unidade discursiva lições. Esta não faz referência à lição de casa da escola, mas a aprendizados, experiências, vivências, análises, tomadas de decisões que o presidente deveria ter efetivado em relação à pandemia do Covid-19 e mesmo sansões pela omissão ou falta de presteza na tomada dessas ações.

Essa palavra só se torna viva quando reflete a linguagem interior, ou seja, quando há consciência, pois, segundo Voloshinóv/Bajtin (1998, p. 39), toda a vida interior do homem estabelece-se em estreita relação com os meios de expressá-la, sendo que, sem linguagem interior não existe consciência, do mesmo modo que não existe linguagem exterior sem linguagem interior.

Tchougounnikov (2005, p. 14, In: Zandwais, 2005), citando Medviédev, aponta que a palavra viva está impressa em um enunciado concreto e o ideologema equivale à avaliação social, sendo que esta aglutina a parte material da palavra a seu sentido. Desse modo (VOLOSHINÓV/BAJTIN, 1998, p. 34, ênfase do autor) 


\section{RECIMA21 - REVISTA CIENTÍFICA MULTIDISCIPLINAR}

DESAFIOS DA EDUCAÇÃo REFLETIDOS E REFRATADOS NA MÍDIA DURANTE A PANDEMIA COVID19

Sonia Sueli Berti Pinto, Miriam Bauab Puzzo

a avaliação social se encontra em cada palavra viva, pois a palavra entra em um enunciado concreto singular. Eis porque na língua, enquanto sistema linguístico abstrato, não encontramos a avaliação social. Para Volochinov, aliás, Bakhtin, o ideológico e o semiótico constituem uma instância vivificante, animadora, que veicula a respiração da vida. (TCHOUGOUNNIKOV, 2005, p. 14, In: ZANDWAIS, 2005).

As imagens, a disposição gráfica dos elementos, os destaques das unidades discursivas em negrito são valorações axiológicas do sujeito/autor que, dependendo do repertório do leitor presumido, podem acionar sensações/emoções representando as avaliações sociais que os sujeitos depreendem dos enunciados concretos. Nas avaliações sociais encontra-se a entonação expressiva do sujeito/autor/leitor, a palavra viva, plena de avaliação social. É ela que dá cor ao sentido e ao som, aproximando-os, imbricando-os na constituição do enunciado (MEDVIÉDEV, 2012, p. 185).

\section{CONDERAÇÕES FINAIS}

A teoria dialógica da linguagem que fundamenta as análises da crônica e das charges, permite observar as relações dialógicas que se estabelecem entre os enunciadores e o contexto social. Elas denunciam os problemas que afetam a sociedade brasileira neste momento de crise sanitária e de um governo que não apresenta um projeto que minimize os efeitos negativos decorrentes da pandemia do Covid19. A educação sem o apoio dos governos Federal, Estadual e Municipal, que minimizem a crise social e sem ministros que efetivamente se preocupem com a formação educacional da população, como sugerem as charges de Caco Galhardo, além dos problemas enfrentados no convívio familiar, como a crônica de Antonio Prata expõe, afeta de modo crucial a população em geral. O material publicado motiva atitudes responsivas em várias esferas de produção e circulação dos gêneros, evidenciando os posicionamentos axiológicos e estéticos de seus autores, como discute Sobral (2010) ao tratar da teoria bakhtiniana sobre esses conceitos. 0 humor nas charges ressalta com ironia a situação caótica em que se encontra a educação em meio a esse contexto, por meio de imagens verbo-visuais, enquanto a crônica explicita nas imagens verbais o resultado desse desencontro entre atitudes governamentais e os conflitos familiares.

Caco Galhardo e Antonio Prata como autores responsáveis por enunciados que circulam na mídia impressa, assumem seu papel de sujeitos que reagem ativamente aos fatos decorrentes das condições precárias que a população enfrenta. Tanto as charges quanto a crônica demonstram os posicionamentos valorativos de seus autores.

$\mathrm{Na}$ contramão das diretrizes educacionais brasileiras expressas em duas leis que regulamentam e complementam a do direito à Educação, qual sejam: o Estatuto da Criança e do Adolescente (ECA), de 1990; e a Lei de Diretrizes e Bases da Educação Nacional (LDBEN), de 1996, o governo atual ignora tal prioridade como as charges procuram ironicamente denunciar.

Nos exemplos analisados, ambos os autores em seus enunciados concretos enfatizam os problemas nacionais de modo a responder ativamente a eles, expressando seus pontos de vista 


\section{RECIMA21 - REVISTA CIENTÍFICA MULTIDISCIPLINAR}

DESAFIOS DA EDUCAÇÃo REFLETIDOS E REFRATADOS NA MÍDIA DURANTE A PANDEMIA COVID19 Sonia Sueli Berti Pinto, Miriam Bauab Puzzo

éticos e estéticos, como pontua Bakhtin (1977), diante do contexto social e pandêmico, aguardando atitudes responsivas do público leitor.

\section{REFERÊNCIAS}

BAKHTIN, M. M. Os gêneros do discurso. TOrganização, tradução e notas de Paulo Bezerra. São Paulo: Editora 34, 2016.

BAJTIN, M. M. Hacia una filosofía del acto ético.Tradução del Ruso Tatiana Bubnova. San Juan: Universidad de Puerto Rico, 1997.

BRAIT, B. Olhar e ver: verbo-visualidade em perspectiva dialógica. In.: Bakhtiniana. Revista de Estudos do Discurso, São Paulo v. 8 n. 2, p. 43-66, jul/dec. 2013.

BRAIT, B. Tramas verbo-visuais da linguagem. In.: Literatura e outras linguagens. São Paulo: Contexto, 2010. p. 193-228.

BRASIL. LEI № 13.979, DE 6 DE FEVEREIRO DE 2020. Dispõe sobre as medidas para enfrentamento da emergência de saúde pública de importância internacional decorrente do coronavírus responsável pelo surto de 2019. Brasília: Casa Civil, 2019. Disponível em: http://www.planalto.gov.br/ccivil 03/ ato2019-2022/2020/lei//13979.htm Acesso em 10 fev. 2021.

BRASIL. DECRETO № 9.235, DE 15 DE DEZEMBRO DE 2017. Dispõe sobre o exercício das funções de regulação, supervisão e avaliação das instituições de educação superior e dos cursos superiores de

graduação e de pós-graduação no sistema federal de ensino. Brasília: ABMES, 2017. Disponível em: https://abmes.org.br/legislacoes/detalhe/2289. Acesso em 10 fev. 2021.

BRASIL. Constituição (1988). Constituição da República Federativa do Brasil. Brasília, DF. Senado, 1988.

BRASIL. LEI № 8.069, DE 13 DE JULHO DE 1990. Dispõe sobre o Estatuto da Criança e do Adolescente e dá outras providências. Brasília: Casa Civil, 1990. Disponível em: https://www.gov.br/mdh/pt-br/centrais-de-conteudo/crianca-e-adolescente/estatuto-da-crianca-e-doadolescente-versao-2019.pdf. Acesso em: 25 jan. 2021.

BRASIL. LEI № 9.394, DE 20 DE DEZEMBRO DE 1996 (LDB). Estabelece as diretrizes e bases da educação nacional. Brasília: Casa Civil, 1996. Disponível em: http://www.planalto.gov.br/ccivil 03/leis/L9394compilado.htm. Acesso em: 25 jan. 2021.

BRASIL. Lei no $\mathbf{1 0 . 4 0 6}$ de 10 de janeiro de 2002. Institui o Código Civil. Brasília: Casa Civil, 2002. Disponível em: http://www.planalto.gov.br/ccivil 03/leis/2002/L10406.htm. Acesso em: 25 out. 2020.

BRASIL. Decreto Legislativo no 6, de 2020. Reconhece, para os fins do art. 65 da Lei Complementar $n^{\circ} 101$, de 4 de maio de 2000, a ocorrência do estado de calamidade pública, nos termos da solicitação do Presidente da República encaminhada por meio da Mensagem no 93, de 18 de março de 2020. Brasília: Casa Civil, 2020. Disponível em: http://www.planalto.gov.br/ccivil 03/portaria/DLG6-2020.htm. Acesso em: 25 nov. 2020. 


\section{RECIMA21 - REVISTA CIENTÍFICA MULTIDISCIPLINAR}

DESAFIOS DA EDUCAÇÃo REFLETIDOS E REFRATADOS NA MÍDIA DURANTE A PANDEMIA COVID19 Sonia Sueli Berti Pinto, Miriam Bauab Puzzo

BRASIL. Portaria no 454, de 20 de março de 2020. Declara, em todo o território nacional, o estado de transmissão comunitária do coronavírus (covid-19). Brasília: Casa Civil, 2020. Disponível em: http://www.planalto.gov.br/ccivil 03/portaria/prt454-20-ms.htm. Acesso em: 25 jan. 2021.

BRASIL. PORTARIA № 544, DE 16 DE JUNHO DE 2020. Dispõe sobre a substituição das aulas presenciais por aulas em meios digitais, enquanto durar a situação de pandemia do novo coronavírus - Covid-19, e revoga as Portarias MEC ํo 343, de 17 de março de 2020, oㅜ 345, de 19 de março de 2020, e no 473, de 12 de maio de 2020. Brasília: Casa Civil, 2020. Disponível em; https://abmes.org.br/legislacoes/detalhe/3185/portaria-mec-n-544-2020. Acesso em 25 jan. 2021.

BRASIL. PARECER CNE-CP № 11, DE 07 DE JULHO DE 2020. Brasília: ABMES, 2020. Disponível em: https://abmes.org.br/legislacoes/detalhe/3264/parecer-cne-cp-n-11. Acesso em: 25 jan. 2021.

BRASIL. RESOLUÇÃO STJ/GP N. 4 DE 16 DE MARÇO DE 2020. Estabelece medidas temporárias de prevenção ao contágio pelo novo coronavírus (COVID-19), considerando a classificação de pandemia pela Organização Mundial de Saúde (OMS). Brasília: STJ, 2020. Disponível em: https://www.sti.jus.br/sites/portalp/Paginas/Comunicacao/Noticias/Acesse-a-integra-daresolucao.aspx. Acesso em: 25 jan. 2021.

BRASIL. Atos do Poder Executivo. MEDIDA PROVISÓRIA no 926, de 20.3.2020, Publicada no DOU de 20.3.2020 - Edição extra - G. Altera a Lei no 13.979, de 6 de fevereiro de 2020, para dispor sobre procedimentos para aquisição de bens, serviços e insumos destinados ao enfrentamento da emergência de saúde pública de importância internacional decorrente do coronavírus. Brasília: Diário Oficial da União, 2020. Disponível em: https://www.in.gov.br/en/web/dou/-/medida-provisoria-n-926de-20-de-marco-de-2020-249094248. Acesso em: 20 dez. 2020.

BRASIL. Atos do Poder Legislativo. LEI № 13.979, de 6.2.2020, Publicada no DOU de 7.2.2020. Dispõe sobre as medidas para enfrentamento da emergência de saúde pública de importância internacional decorrente do coronavírus responsável pelo surto de 2019. Brasília: Diário Oficial da União, 2020. Disponível em: https://www.in.gov.br/en/web/dou/-/lei-n-13.979-de-6-de-fevereiro-de2020-242078735. Acesso em: $20 \mathrm{dez} .2020$.

BRASIL. Presidência da República/Casa Civil. PORTARIA № 126, de 19.3.2020, Publicado no DOU de 19.03.2020 - Edição extra-E e republicado no DOU de Edição extra-D. Brasília: Diário Oficial da União, 2020. Disponível em: https://www.in.gov.br/en/web/dou/-/portaria-n-126-de-19-de-marco-de2020-248881688. Acesso em: $20 \mathrm{dez} .2020$.

BRASIL. Ministério da Saúde/Gabinete do Ministro. PORTARIA no 356/3020, que regulamenta as medidas para o enfrentamento da emergência de saúde pública de importância internacional em decorrência do coronavírus (Covid-9). A medida regulamenta a Lei 13.979/20. Brasília: Diário Oficial da União, 2020. Disponível em: https:/www.in.gov.br/en/web/dou/-/portaria-n-356-de-11-de-marcode-2020-247538346. Acesso em: 20 dez. 2020.

BRASIL. Ministério da Saúde/Gabinete do Ministro. PORTARIA no 188/GM/MS de 3 de fevereiro de 2020. Declara Emergência em Saúde Pública de importância Nacional (ESPIN) em decorrência da Infecção Humana pelo novo Coronavírus (2019-nCoV). Brasília: Diário Oficial da União, 2020. Disponível em: https://www.in.gov.br/web/dou/-/portaria-n-188-de-3-de-fevereiro-de-2020-241408388. Acesso em: 20 dez. 2020.

BRASIL. Decreto no 10.282/2020. Regulamenta a Lei o 13.979, de 6 de fevereiro de 2020, para definir os serviços públicos e as atividades essenciais. Brasília: Casa Civil, 2020. Disponível em: http://www.planalto.gov.br/ccivil 03/ ato2019-2022/2020/decreto/D10282.htm. Acesso em: 20 out. 2020.

BRASIL. PORTARIA MEC № 1.030, DE 01 DE DEZEMBRO DE 2020. Dispõe sobre o retorno às aulas presenciais e sobre caráter excepcional de utilização de recursos educacionais digitais para integralização da carga horária das atividades pedagógicas enquanto durar a situação de pandemia 


\section{RECIMA21 - REVISTA CIENTÍFICA MULTIDISCIPLINAR}

DESAFIOS DA EDUCAÇÃo REFLETIDOS E REFRATADOS NA MÍDIA DURANTE A PANDEMIA COVID19 Sonia Sueli Berti Pinto, Miriam Bauab Puzzo

do novo coronavírus - Covid-19. Brasília: ABMES, 2020. Disponível em: https://abmes.org.br/arquivos/legislacoes/portaria1030 02122020.pdf. Acesso em: 25 jan. 2021.

BRASIL. Portaria MEC № 1.038, de 07 de dezembro de 2020. Brasília: ABMES, 2020. Disponível em: https://abmes.org.br/arquivos/legislacoes/Portaria-mec-1038-2020-12-07.pdf. Acesso em: 10 fev. 2021.

DONDIS, D. A. Sintaxe da linguagem visual. São Paulo: Martins Fontes, 2003.

GALHARDO, C. Charges in Piauí, no 164, maio 2020. Disponível em: https://twitter.com/revistapiaui/status/1267199171725086721. Acesso em: 10 fev. 2021.

MEDVIÉDEV, P. N. O método formal nos estudos literários: introdução crítica a uma poética sociológica. São Paulo: Contexto, 2012.

PIOVESAN, Flávia. Direitos humanos e o direito constitucional internacional. 4. ed. São Paulo: Max Limonad, 2000.

PRATA, A. Tela, cautela, nutela in Folha de S. Paulo, llustrada,12 set, 2020. Disponível em: http://cartunistasolda.com.br/tag/tela-cautela-e-nutella/. Acesso em 10 fev. 2021.

SOBRAL, A. A estética em Bakhtin (literatura, poética e estética). In.: PAULA, L.; STAFUZZA, G. (Orgs.) Círculo de Bakhtin: teoria inclassificável. Campinas: Mercado de Letras, 2010, p. 53-88.

SOBRAL, A. Ético e estético: na vida, na arte e na pesquisa em Ciências Humanas. In.: BRAIT, B. (Org.) Bakhtin: conceitos-chave. São Paulo: Contexto, 2005, p.103-121.

VOLÓCHINOV, M. M. Marxismo e filosofia da linguagem. São Paulo: Editora 34, 2017.

VOLOSHINOV, V.; BAJTIN, M. “¿Qué es el Lenguaje?”. Buenos Aires. Almagesto. 1998.

VOLOCHINOV, V. (M. M. Bakhtin). A palavra na vida e na poesia. Introdução ao problema da poética sociológica. In.: VOLOCHÍNOV, V. N.; BAKHTIN, M. M. Palavra própria e palavra outra na sintaxe da enunciação. São Carlos: Pedro \& João Ed., 2011. p.145-181.

VOLOSHINOV, V. N. Le discours dans la vie et le discours dans la poésie: Contribution à une poétique sociologique. In.: TODOROV, T. Mikaïl Bakhtine le principe dialogique. Paris: Seuil, 1981. p.181-215.

ZANDWAIS, A. (org.). História das ideias: diálogos entre linguagem, cultura e história. Passo Fundo: Editora Universidade de Passo Fundo, 2012. 312 p.

ZANDWAIS, A. O papel das leituras engajadas em Marxismo e filosofia da linguagem. Conexão Letras. Porto Alegre, v. 4, n. 4, p. 31-40, 2009.

ZANDWAIS, A. (org.) Mikhail Bakhtin: contribuições para a filosofia da linguagem e estudos discursivos. Porto Alegre: Editora Sagra Luzzatto, 2005. 


\section{RECIMA21 - REVISTA CIENTÍFICA MULTIDISCIPLINAR}

DESAFIOS DA EDUCAÇÃo REFLETIDOS E REFRATADOS NA MÍDIA DURANTE A PANDEMIA COVID19 Sonia Sueli Berti Pinto, Miriam Bauab Puzzo

\section{ANEXOS}

\section{TELA, CAUTELA, NUTELLA}

"Queridos pais e mães. Não sei se já falaram disso aqui no grupo: como é que seus filhos tão lidando com o ensino remoto? Os meus tão muito ansiosos, não querem fazer, choram... Tô em dúvida se insisto, se desencano do homeschooling ou se desencano do meu emprego e fico todas as tardes ao lado deles, ajudando. Digam lá."

Gosto muito da escola dos meus filhos. Mais importante, eles gostam. Até março, ela, de 7 e ele, de 5 , iam animados e voltavam entusiasmados, contando que "o polvo tem oito pernas", "quando é dia aqui em casa é de noite lá no Japão", "a mãe do Ernesto nasceu num país que tem nome daquele frango que a gente come no Natal e a música de ninar, lá, é assim: 'los pollitos dicen, pío pío pío..."'. Os dois nunca reclamaram de ir pro colégio, mas se um dia fizessem uma birra homérica e dissessem "hoje eu não vou!", eu ignoraria. Confio na escola, sei que fará bem a eles e que um pouco de sofrimento faz parte do aprendizado, paciência.

Cinco horas por dia na frente de um iPad fazendo aula online, porém, é inédito na história da humanidade e comecei a me perguntar se forçá-los a serem cobaias, com tanto sofrimento, neste experimento social, não era como submetê-los a uma espécie de cloroquina pedagógica antes de termos estudos confiáveis sobre os efeitos adversos.

É difícil para crianças pequenas lembrar de abrir e fechar o microfone (nem nós lembramos), achar os links certos, encontrar as fichas dentro das pastas. Falar sem serem ouvidos. Reduzir todo o espaço escolar a uma telinha. Percebo que meus filhos se sentem sempre errando, em falta, abrindo o microfone quando tem que fechar ou pegando a ficha do broto do feijão na hora de pegar a do Sistema Solar.

(Eu e a minha mulher já brigamos algumas vezes. Ela tem certeza de que eu acordo de madrugada só pra esconder o jogo da memória de fundo do mar no meio das fichas de alfabetização, mas eu sei que é ela quem tenta me enlouquecer moqueando a ficha das cores em inglês no meio da pasta de matemática).

Fico com pena das esforçadíssimas professoras, que parecem estar tentando ensaiar "O Lago dos Cisnes" com um corpo de baile composto por Gremlins. Mas fico com mais pena ainda dos meus pequenos Gremlins, tropeçando no palco.

A escola está fazendo o que pode -muito em cima das nossas demandas de mães e pais preocupados com a perda de conteúdo e desesperados com crianças presas há seis meses em apartamentos. Mas, talvez, entre a nossa aflição e a dos educadores, as crianças estejam sendo expostas a uma tensão, a uma ansiedade e a um tédio desnecessários e danosos.

Felizmente, o grupo de zap da primeira série me tranquilizou. Alguns pais conseguem dedicar as tardes às crianças e têm tido um resultado satisfatório. Alguns desistiram por completo e estão plantando alface com as crianças na casa da avó em Araraquara. Alguns limitaram o número de horas. Outros misturam português com Patrulha Canina. Outros encheram a banheira de Nutella em 


\section{RECIMA21 - REVISTA CIENTÍFICA MULTIDISCIPLINAR}

DESAFIOS DA EDUCAÇÃo REFLETIDOS E REFRATADOS NA MÍDIA DURANTE A PANDEMIA COVID19 Sonia Sueli Berti Pinto, Miriam Bauab Puzzo março e só vão se preocupar com a escola quando a criança terminar de lamber a última manchinha marrom. Falei com a coordenadora, que também foi bacana ao aceitar que montemos um formato possível para a família.

Estamos vivendo um estado de exceção. Ninguém tem fórmula para a retomada da economia, a sobrevivência dos casamentos, para os lutos sem velórios ou sequer para a prática de atividades físicas ao ar livre. É bom expormos as crianças às aulas on-line com bastante cautela -e se mesmo a cautela for inútil contra o sofrimento, talvez não seja de todo o mal apelarmos para a Nutella.

\section{Antonio Prata}

